\title{
Climatic warming causes regime shifts in lake food webs
}

\begin{abstract}
Spring clear water phases caused by grazing of zooplankton on algae are among the most spectacular and well-studied events in lake plankton dynamics. Such clear water phases are also important as windows of opportunity for recovery of aquatic vegetation and biodiversity in shallow waters. Here we use long time series from 71 shallow lakes to demonstrate that the probability of clear water phase increases with the temperature of lake water. We demonstrate that lake temperature has risen significantly over the past decades and is highly correlated with oscillations in the North Atlantic climate system. We also show a distinct climate-related shift in the timing of clear water phases in the shallow lakes as well as in an independent set of central European lakes. Simulations with a seasonally forced plankton model confirm that temperature rise is a plausible explanation for the observed changes.
\end{abstract}

A spring clear water phase is a common phenomenon in lakes (Sommer et al. 1986; Carpenter et al. 1993; Rudstam et al. 1993) but does not always occur. Indeed, most hypertrophic shallow lakes simply remain turbid throughout the year (Hosper and Meijer 1986; Sas 1989). Also, timing of the clear water phase can vary strongly (Scheffer et al. 1997). To check for relationships between occurrence of clear water phases and climatic conditions, we analyzed 257 seasonal patterns of chlorophyll $a$ concentrations obtained between 1975 and 1991 from 71 shallow Dutch lakes sampled at least once every month. We selected the lowest summer chlorophyll $a$ concentration between 1 April and 1 August in each annual time series and considered it a clear water phase if it represented a concentration of less than $5 \mu \mathrm{g} \mathrm{L}{ }^{-1}$. We related the occurrence of these clear water phases in Dutch lakes to a large scale climatic phenomenon known as the North Atlantic oscillation (NAO) using the NAO winter index (http:// www.cgd.ucar.edu:80/cas/climind/). This climatic oscillation has been shown to influence a variety of ecosystems across the Northern Hemisphere (Ottersen et al. 2001) including several lakes (Weyhenmeyer et al. 1999; George 2000; Straile 2000; Straile and Adrian 2000). In addition to the NAO, we use the water temperature of one of our lakes (Lake Veluwe), where the temperature has been recorded on a daily basis since 1959 as a more direct indicator of changing climatic conditions for the Dutch lakes. To complement the analyses of the geographically and physically homogeneous set of Dutch lakes, we analyzed an independent data set of 136 seasonal time series of transparency from 28 central European lakes in which clear water phases were defined as the highest Secchi disk reading after the spring algal bloom.

The temperature of Lake Veluwe increased significantly since 1959 (Fig. 1). This trend occurs for water temperature in all seasons except spring (Table 1). Much of the variation in lake water temperature can be explained from the NAO winter

\section{Konstanzer Online-Publikations-System (KOPS)}

URL: http://www.ub.uni-konstanz.de/kops/volltexte/2007/3975/

URN: http://nbn-resolving.de/urn:nbn:de:bsz:352-opus-39750 


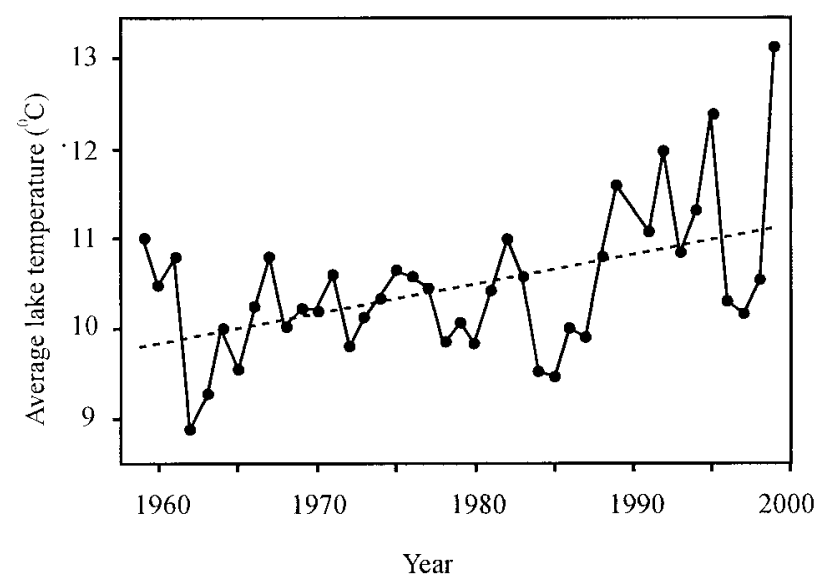

Fig. 1. Increase of average year temperature in Lake Veluwe over the past decades.

climate index (Fig. 2). Not surprisingly, the correlation between lake temperature and the NAO winter index is most pronounced in winter when the index is defined, but even subsequent spring and summer temperatures of the lake remain strongly correlated to the NAO winter index (Table 1).

Regression analysis shows that clear water phases in the Dutch shallow lakes come on an earlier day $(d)$ in years with a high NAO index in the preceding winter $(d=160-$ $6.3 \times \mathrm{NAO}$; slope $p<0.01$; adjusted $R^{2}=0.21$ ). A similar, but smaller, time shift is observed in the geographically much more diverse set of Central European lakes, where altitude (ALT) also explains a significant part of the variance $(d=155.5-2.9 \times \mathrm{NAO}+0.03 \times$ ALT; slopes $p<0.001$; adjusted $R^{2}=0.26$ ). In view of the correlation between lake temperatures and the NAO index, it seems reasonable to assume that temperature is a major causal link between the NAO atmospheric pressure ratio and plankton dynamics. Using the Lake Veluwe data as an indicator of temperature in the geographically close set of Dutch shallow lakes, clear water phases are estimated to appear about 1 week earlier on average if the first quarter water temperature $\left(T_{1}\right)$ is one degree higher $\left(d=184-8.4 \times T_{1}\right.$; slope $p<0.01$; adjusted

Table 1. Temperature rise of lake Veluwe and its correlation to the North Atlantic Oscillation. Over the period 1959-1999 the average annual temperature of the water $\left(T_{\text {annual }}\right)$ in Lake Veluwe, as well as water temperature during the first three quarters $\left(T_{1-3}\right)$, is strongly correlated to the North Atlantic Oscillation winter index (NAO). Both NAO and average water temperatures (except in the second quarter) increased significantly with time (year) over these decades.

\begin{tabular}{llllllll}
\hline \hline & NAO & Year & $T_{\text {annual }}$ & \multicolumn{1}{c}{$T_{1}$} & \multicolumn{1}{c}{$T_{2}$} & \multicolumn{1}{c}{$T_{3}$} & \multicolumn{1}{c}{$T_{4}$} \\
\hline NAO & 1 & $0.483^{*}$ & $0.604^{*}$ & $0.749^{*}$ & $0.489^{*}$ & $0.341 \dagger$ & 0.216 \\
Year & $0.483^{*}$ & 1 & $0.481^{*}$ & $0.443^{*}$ & 0.197 & $0.479^{*}$ & $0.501^{*}$ \\
$T_{\text {annual }}$ & $0.604^{*}$ & $0.481^{*}$ & 1 & $0.804^{*}$ & $0.704^{*}$ & $0.706^{*}$ & $0.652^{*}$ \\
$T_{1}$ & $0.749^{*}$ & $0.443^{*}$ & $0.804^{*}$ & 1 & $0.562^{*}$ & $0.443^{*}$ & 0.285 \\
$T_{2}$ & $0.489^{*}$ & 0.197 & $0.704^{*}$ & $0.562^{*}$ & 1 & 0.311 & 0.264 \\
$T_{3}$ & $0.341 \dagger$ & $0.479^{*}$ & $0.706^{*}$ & $0.443^{*}$ & 0.311 & 1 & $0.480^{*}$ \\
$T_{4}$ & 0.216 & $0.501^{*}$ & $0.652^{*}$ & 0.285 & 0.264 & $0.480^{*}$ & 1 \\
\hline
\end{tabular}

* Two-tailed significance at the 0.01 level.

$\dagger$ Two-tailed significance at the 0.05 level.

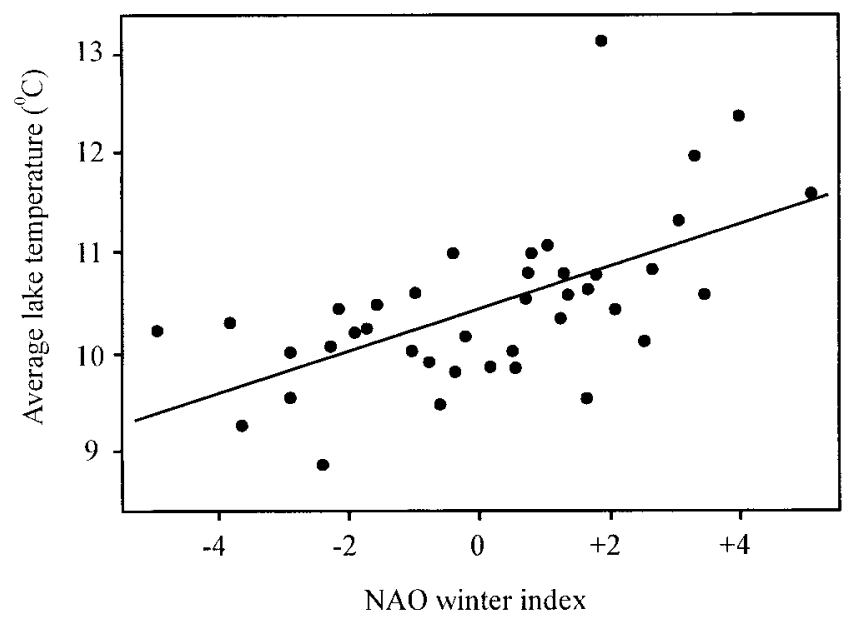

Fig. 2. Relationship between the North Atlantic oscillation winter index and average year temperature in Lake Veluwe over the period 1959-1999.
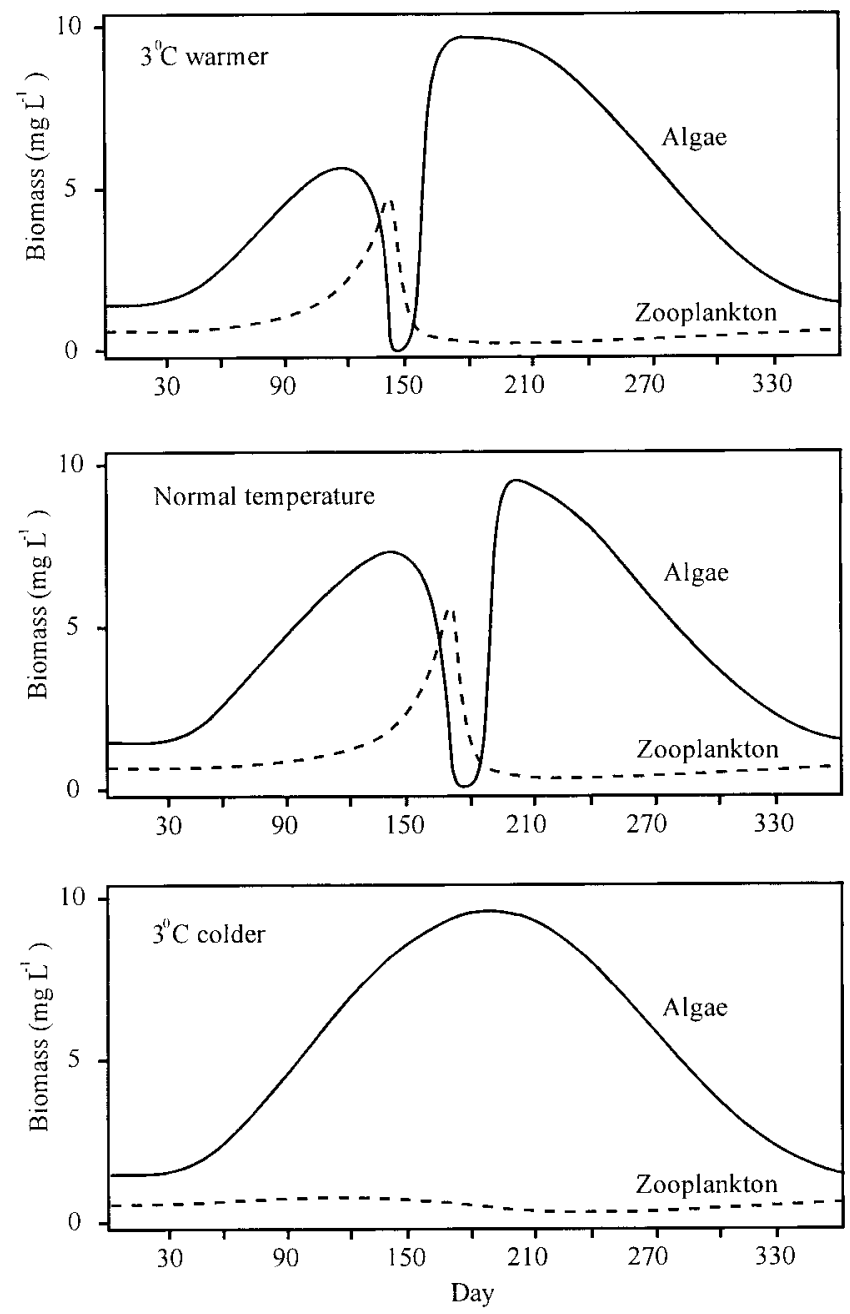

Fig. 3. Simulated effect of temperature change on seasonal plankton dynamics. The lower panel represents one year out of a chaotic time series with sporadic clear water phases. (Simulations with $q=0.812,1$ and 1.231 for upper, middle, and lower panels, and $f=0.0965$ in all panels.) 
Table 2. Parameters of the seasonal plankton model.

\begin{tabular}{|c|c|c|c|}
\hline$r$ & 0.5 & day $^{-1}$ & maximum algal growth rate \\
\hline$K$ & 10 & mg DWT L $\mathrm{L}^{-1}$ & algal carrying capacity \\
\hline$g$ & 0.4 & day $^{-1}$ & maximum zooplankton grazing rate \\
\hline$h_{A}$ & 0.6 & mg DWT L L & $\begin{array}{l}\text { half-saturation algal concentration } \\
\text { for zooplankton grazing }\end{array}$ \\
\hline$d$ & 0.01 & - & $\begin{array}{l}\text { inflow rate of algae from ungrazed } \\
\text { parts }\end{array}$ \\
\hline$e$ & 0.6 & - & $\begin{array}{l}\text { efficiency of food conversion to } \\
\text { growth }\end{array}$ \\
\hline$m$ & 0.15 & day $^{-1}$ & loss rate of zooplankton \\
\hline$h_{z}$ & 0.5 & mg DWT L $\mathrm{L}^{-1}$ & $\begin{array}{l}\text { half-saturation zooplankton concen- } \\
\text { tration for fish predation }\end{array}$ \\
\hline$\varepsilon$ & 0.7 & - & seasonal forcing strength \\
\hline$t$ & - & day & day of the year \\
\hline
\end{tabular}

$\left.R^{2}=0.20\right)$. Explained variance is about the same as for the regression against the NAO index, and quite high in view of the fact that the sample intervals in these time series (24 weeks) are large compared to the duration (roughly 1 month) of a typical clear water phase.

Not only the timing but also the probability that a clear water phase occurs is related to climatic conditions. In the studied central European lakes, clear water phases occur every year. However, in the Dutch hypertrophic shallow lakes, clear water phases are relatively rare events. Multiple logistic regression shows that the probability of a clear water phase in the Dutch lakes is positively related to NAO index $(r=$ $0.335, p<0.005)$ and decreases with the average chlorophyll $a$ concentration $(r=-0.067, p<0.001)$. The finding that more eutrophic lakes (with higher average chlorophyll $a$ levels) have lower chances for a clear water phase has been found earlier and is likely due to high fish predation on Daphnia (Scheffer et al. 1997). The puzzling climatic effect is new.
In order to check whether the enhanced probability of clear water phases and their time shift may reasonably be explained from the change in water temperature, we used a simulation model. Although many processes are involved in determining the seasonal dynamics of lake plankton, the occurrence of clear water phases and other common patterns in shallow lakes can be reproduced with remarkable realism by a simple periodically forced algae-zooplankton model (Scheffer et al. 1997) of seasonal plankton dynamics of algae $(A)$ and zooplankton $(Z)$ :

$$
\begin{aligned}
\frac{d A}{d t}= & q \sigma_{(t)} r A\left(1-\frac{A}{\sigma_{(t)} K}\right)-q \sigma_{(t)} g Z \frac{A}{A+h_{A}} \\
& +d\left(\sigma_{(t)} K-A\right) \\
\frac{d Z}{d t}= & q \sigma_{(t)} e g Z \frac{A}{A+h_{A}}-q \sigma_{(t)} m Z-q \sigma_{(t)} \sigma_{(t)} F \frac{Z^{2}}{Z^{2}+h_{Z}^{2}}
\end{aligned}
$$

The basic formulation is rather classical and has been used in various analyses before (Gragnani et al. 1999). Seasonal cycles of light, temperature and planktivorous fish abundance are represented by a sinusoidal variation, $\sigma_{t}$, with time, $t$, of the value of the relevant model parameters (Scheffer et al. 1997):

$$
\sigma_{(t)}=\frac{1-\varepsilon \cos \left(\frac{2 \pi t}{365}\right)}{1+\varepsilon}
$$

Effects of change in average temperature of $x^{\circ} \mathrm{C}$ are mimicked through the parameter $q=2^{x / 10}$, which reflects the fact that most biological process rates roughly double every $10^{\circ} \mathrm{C}$. Reference values, dimensions, and interpretations of other parameters are summarized in Table 2.

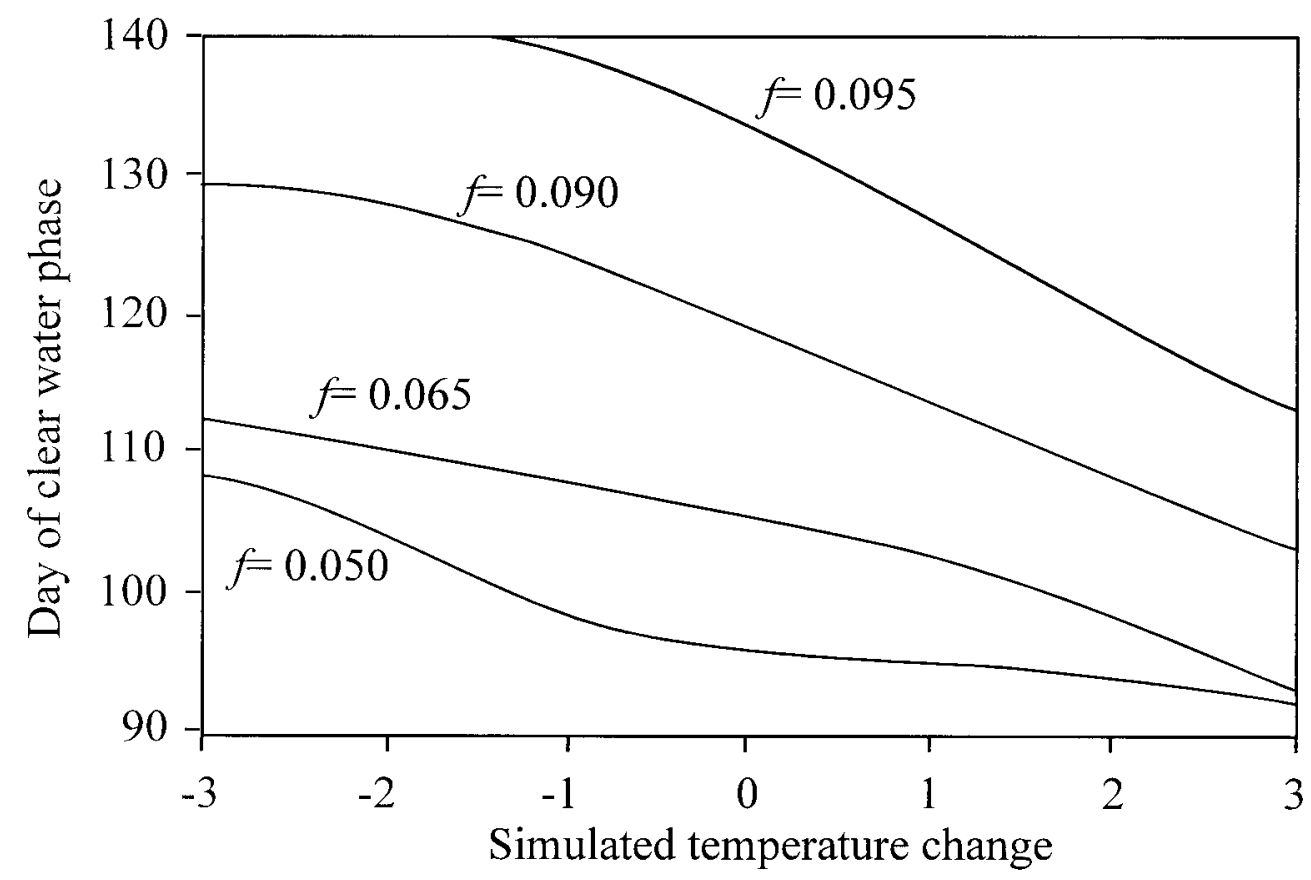

Fig. 4. Simulated effect of change in average water temperature on the day of the year at which simulated clear water phases occur, for four different fish densities $(f)$ as indicated. 
We used this model to simulate the effect of change in average lake water temperature. The model predicts that with reduced temperature or increasing fish densities, clear water phases first shift to a later day (Figs. 3 and 4). Beyond a certain temperature change, clear water phases start to be absent in some but not all years following a sequence of regimes in which windows of chaotic dynamics alternate with regular multiyear cycles (not shown). Eventually clear water phases become entirely absent. The critical fish density at which clear water phases are absent decreases by about $5 \%$ for every degree of simulated temperature drop. Thus lakes that are on the edge of having too many fish for clear water phases are predicted to lose them in colder years. In contrast, lake warming results in more and in earlier clear water phases. In lakes with high fish densities a time shift of about $10 \mathrm{~d}$ per degree centigrade is predicted (Fig. 3). For more moderate fish densities, simulated clear water phases shift about 3-7 d with each degree of temperature change (Fig. 4). The $8.4 \mathrm{~d}$ time shift suggested by regression analysis of field data against temperature in Dutch lakes corresponds well to the predicted shift for very high fish densities present in these lakes. For the diverse set of Central European lakes we do not have good temperature indicators. However, the highly significant shift of $3 \mathrm{~d}$ per $100 \mathrm{~m}$ altitude indicates a temperature effect of about $5 \mathrm{~d}$ per degree centigrade, which is also well in line with the modeled temperature effect.

Although the model is an admittedly crude simplification of reality, the general correspondence between field patterns and model predictions indicates that lake warming is indeed a plausible explanation for the observed changes in plankton dynamics. The time shift effect demonstrates that not only the life cycle of individual species, but also the dynamics of entire food webs may be profoundly affected by climate change. Perhaps more importantly, the fact that clear water phases can be eliminated depending on temperature illustrates that under some conditions small climatic changes may trigger major regime shifts in ecosystems. In shallow lakes such planktonic regime shifts have the potential to trigger even larger ecosystem changes, as clear water phases open a crucial window of opportunity for the recolonization of submerged vegetation, which is key to the recovery of biodiversity in these often badly degraded ecosystems (Scheffer 1998).

\section{Marten Scheffer ${ }^{1}$}

Department of Aquatic Ecology and Water

Quality Management

Agricultural University, Wageningen

P.O. Box 8080

NL-6700 DD Wageningen, The Netherlands

\footnotetext{
${ }^{1}$ Corresponding author (marten.scheffer@aqec.wkao.wau.nl).
}

\section{Acknowledgements}

We thank Ebo Kasemier for his kind help in the preparation of the temperature data. Secchi disk data from Lake Zürich, Müggelsee, and Pluss-See were provided by S. Gammeter, Wasserversorgung Zürich; R. Adrian, Institut für Gewässerökologie und Binnenfischerei, Berlin; and W. Lampert, Max-Plank-Institut für Limnologie, Plön. Dietmar Straile was supported by the EU project response of European freshwater lakes to environmental and climatic change (REFLECT, contract number: ENV4-CT97-0453).

\section{Dietmar Straile}

Limnologisches Institut

Universität Konstanz

D-78457 Konstanz, Germany

Egbert H. van Nes

Department of Aquatic Ecology and Water

Quality Management

Agricultural University, Wageningen

P.O. Box 8080

NL-6700 DD Wageningen, The Netherlands

Harry Hosper

RIZA

PO Box 17

8200 AA Lelystad, the Netherlands

\section{References}

Carpenter, S. R., R. C. Lathrop, and A. Munoz-Del-Rio. 1993. Comparison of dynamic models for edible phytoplankton. Can. J. Fish. Aquat. Sci. 50: 1757-1767.

GEORGE, D. G. 2000. The impact of regional-scale changes in the weather on the long-term dynamics of Eudiaptomus and Daphnia in Esthwaite Water, Cumbria. Freshw. Biol. 45: 111-121.

Gragnani, A., M. Scheffer, and S. Rinaldi. 1999. Top-down control of cyanobacteria: A theoretical analysis. Am. Nat. 153: $59-72$.

Hosper, S. H., AND M. L. MeIJER. 1986. Control of phosphorus loading and flushing as restoration methods for Lake Veluwe, the Netherlands. Hydrobiol. Bull. 20: 183-194.

Ottersen, G., B. Planque, A. Belgrano, E. Post, P. C. Reid, AND N. C. Stenseth. 2001. Ecological effects of the North Atlantic Oscillation. Oecologia 128: 1-14.

Rudstam, L. G., R. C. Lathrop, and S. R. CARpenter. 1993. The rise and fall of a dominant planktivore: Direct and indirect effects on zooplankton. Ecology 74: 303-319.

SAS, H. 1989. Lake restoration by reduction of nutrient loading: Expectations, experiences, extrapolations. Academia Verlag Richarz.

SCHEFFER, M. 1998. Ecology of shallow lakes. Chapman and Hall.

, S. Rinaldi, Y. A. KuZnetsov, and E. H. VAN Nes. 1997. Seasonal dynamics of Daphnia and algae explained as a periodically forced predator-prey system. Oikos 80: 519-532.

Sommer, U., Z. M. Gliwicz, W. Lampert, and A. DunCan. 1986. The plankton ecology group model of seasonal succession of planktonic events in fresh waters. Arch. Hydrobiol. 106: 433472.

STRAILE, D. 2000. Meteorological forcing of plankton dynamics in a large and deep continental European lake. Oecologia 122: $44-50$.

- AND R. AdRIAn. 2000. The North Atlantic oscillation and plankton dynamics in two European lakes-two variations on a general theme. Glob. Chang. Biol. 6: 663-670.

Weyhenmeyer, G. A., T. Blenckner, And K. Pettersson. 1999. Changes of the plankton spring outburst related to the North Atlantic Oscillation. Limnol. Oceanogr. 44: 1788-1792.

Received: 20 March 2001 Accepted: 28 June 2001

Amended: 12 July 2001 